\title{
Does being 'well off' help people with epilepsy cope better? The social impact of epilepsy
}

\author{
Christine Walker ${ }^{\mathrm{a}, \mathrm{b}}$, Chris L. Peterson ${ }^{\mathrm{b}, \mathrm{c}, *}$ \\ a Chronic Illness Alliance Victoria, Australia \\ ${ }^{\mathrm{b}}$ Epilepsy Foundation, Surry Hills, Victoria, Australia \\ ' School of Humanities and Social Sciences, College of the Arts, Social Science and Commerce, Plenty Rd, Bundoora, La Trobe University, Bundoora, Australia
}

\section{A R T I C L E I N F O}

\section{Article history:}

Received 5 July 2016

Accepted 15 November 2016

\section{Keywords:}

Control prosperity

Socio-economic status

\begin{abstract}
A B S T R A C T
Introduction: Studies demonstrate that there is a positive association between socioeconomic status (SES) and personal control where higher SES groups are likely to have higher personal control and better health outcomes. People with epilepsy however usually show lower levels of personal control. This paper aims to explore the relationship between self-rated prosperity and personal control in an epilepsy sample.

Methods: Using the results of the 2013 Australian Epilepsy Longitudinal Survey (AELS) a group was identified who perceived themselves as prosperous or very comfortable. Hypothesising that prosperity would provide greater personal control, we compared this group with other groups from HILDA Wave 11, a random sample of the Australian population surveyed in 2011. HILDA is a household, labour and income study funded by the Australian government.

Results: All respondents in Wave 3 (AELS) had lower levels of personal control than the HILDA Wave 11 groups. In a comparison between Wave 3 of those reporting themselves as prosperous or very comfortable with similar groups in HILDA Wave 11, prosperous people from Wave 3 demonstrated much lower levels of personal control than the HILDA Wave 11 group.

Conclusion: Personal control is considered to have far-reaching consequences for people's health. The effects of stigma and the unpredictability of epilepsy far outweigh the effects of prosperity for people with epilepsy compared to a random sample of the Australian population.
\end{abstract}

(c) 2016 Published by Elsevier, a division of RELX India, Pvt. Ltd on behalf of Indian Epilepsy Society.

\section{Introduction}

Evidence exists that beliefs in personal control are linked to better health outcomes, both psychological and physical. ${ }^{1-3}$ Evidence also exists that there is an association between socioeconomic status (SES) and personal control in relation to health and well-being. ${ }^{4-5}$ Peterson and Stunkard ${ }^{6}$ argued that personal control is based around the beliefs persons have about how they might achieve positive outcomes and avoid negative events. Pearlin and Schooler ${ }^{7}$ have also linked personal control and its effects on stress and consequent health. Other concepts are associated with personal control and sometimes used

\footnotetext{
* Corresponding author at: School of Humanities and Social Sciences, College of the Arts, Social Science and Commerce, Plenty Rd, Bundoora, La Trobe University, Bundoora, Australia.

E-mail addresses: cwalker@chronicillness.org.au (C. Walker), c.peterson@latrobe.edu.au (C.L. Peterson).
}

interchangeably: self-efficacy, powerlessness, learned helplessness and mastery. ${ }^{8,9}$

A number of factors influence the extent to which a person considers him/herself as having control over their own lives. ${ }^{10}$ These include educational level, occupation, income and social position. ${ }^{11,12}$ These are also the domains that comprise SES which may be defined as differential access to scarce resources including health $^{13}$ and thus there are studies that show there is a positive association between SES and perceptions of personal control. ${ }^{4,14,15}$

This association has implications for health, in terms of selfrated health, health outcomes ${ }^{4,5}$ and health maintenance or selfmanagement. ${ }^{16}$ Some studies have demonstrated a strong relationship between higher SES and better health outcomes. For example Ferrie ${ }^{17}$ reports that Marmot's civil service study found that higher SES was linked with lower incidence of coronary heart disease (CHD), while Goldman and Smith ${ }^{18}$ demonstrate that higher SES is related to better health maintenance in both diabetes and HIV. However with some conjecture on the link between wealth and personal control for epilepsy McLaughlan et al. ${ }^{19}$ have 
argued that previous research into personal control in epilepsy has been particularly limiting and the results conflicting.

Hermann and Jacoby ${ }^{20}$ have argued that the experience of dealing with epilepsy may affect people's worldviews and locus of control. They cite studies which have shown a lower sense of personal control amongst epilepsy populations compared to other medical conditions and the general population. Children with epilepsy have been shown to have poorer sense of control compared to those with diabetes and children with orthopaedic conditions.

In this article the study presents data on SES in the epilepsy sample and then analyses the relationship between self-perceived prosperity and personal control. The study investigates that the association between SES and personal control observed in other populations such as people with insulin-dependent diabetes ${ }^{18}$ will be similar to that between self-perceived prosperity and personal control for people with epilepsy It also examines the extent to which seizure frequency and stigma affect personal control. The study examines the relationship between selfperceived wealth and personal control for the sample of people with epilepsy and compares it with an Australian random sample from the HILDA study (HILDA All), and from part of the HILDA sample, being people with a long term health conditions, disability or impairments.

\section{Methods}

Data on the social impact of epilepsy are collected by survey from the Australian Epilepsy Research Register for all Waves of the Australian Epilepsy Longitudinal Study. It is a community sample of people with epilepsy. Of the 883 participants eligible to participate in the 2013 Wave 3 of AELS, 324 (36.7\%) responded. Inclusion criteria were having a diagnosis of epilepsy and being on the AELS register. Data have been collected over three Waves, in 2006, 2010 and in 2013, and in Wave 3 by paper survey and online. Wave 3 collected data on finances and social effects of having epilepsy.

The Wave 3 tool used validated questions to collect data on education, income and employment to compare responses to other longitudinal studies representing the Australian population, such as the Household, Income and Labour Dynamics in Australia Survey (HILDA). Wave 11 of HILDA was chosen as it is the most recent time (2011) that personal control data were collected (sample size 17,612). It is a random sample of the Australian population; a panel study that commenced in 2001 and inclusion criteria was all persons residing in private dwellings. Each Wave of the HILDA study is carried out approximately each year, with a different mix of questions for each wave. Those people with epilepsy and their families who perceive themselves as "well off" have been compared with the whole population in Wave 11 of the HILDA study as well as with a subset of Wave 11, a smaller sample from the same Wave of those only those with a long term health conditions, disability or impairments (adequate sample size 4133). Inclusion criteria were having a long term health condition such as a chronic illness or a disability. In the HILDA study data are collected by interview and self-completed questionnaire. The Wave 3 of AELS contained a version of Pearlin's Sense of Control scale and the Prosperity scale.

Note: The HILDA project was initiated and is funded by the Australian Government Department of Families, Housing, Community Services and Indigenous Affairs (FaHCSIA) and is managed by the Melbourne Institute of Applied Economic and Social Research (Melbourne Institute). The findings and views reported in this report, however, are those of the authors and should not be attributed to either FaHCSIA or the Melbourne Institute. These data are derived from Wave 11 (2011) of the HILDA survey.
Pearlin's Sense of Personal Control scale has seven questions. These refer to the extent to which a person has an internal locus of control, or mastery over events. ${ }^{7}$ Edwards et al., ${ }^{21}$ report that the Pearlin scale is sound psychometrically, has good reliability and that it has convergent validity in a range of different populations. The scale has also been used extensively in Waves of the HILDA study in Australia. Internal reliability has been found in a Canadian population (Cronbach's alpha .76). In validity, low levels of control have been associated with poor mental and general health and with depression. ${ }^{22}$ A Cronbach alpha of .82 and an inter-item correlation of .40 for the 7 item univariate scale were reported in this study. As a univariate scale it has all seven questions in the one scale.

While recognising that the measurement of socioeconomic status has its challenges ${ }^{13}$ data on education, employment status and income was used to discuss the epilepsy sample. Education is regarded as a reliable measure on its own as it gives access to employment and income. ${ }^{23}$ The study has combined this measure with employment status and income to provide a background to the prosperity of the sample.

Oakes and Rossi ${ }^{13}$ suggest that SES measurement aims at capturing 'how levels of inequality and variations in social context affect health outcomes'. They suggest that this requires more of the social context than just the data from these measures. On this basis the study has presented data on family income in the context of the Australian economic and welfare climate. The epilepsy sample has a lower than average family income and as such are more than the average likely to be recipients of government benefits. This may affect their experience of health and illness by limiting access to resources.

In this study a six item scale is used for a self-assessment of Prosperity to gauge the extent to which they perceive themselves as prosperous or poor. Respondents are asked 'given your current needs and financial responsibilities would you say that you and your family are' ... followed by six response categories from very poor to prosperous.

A scale of nine items was derived from Austin et al., ${ }^{24}$ for the stigma scale used in this study and has been previously discussed in a paper on the previous Wave 2 of the AELS. ${ }^{25}$

Further, a subset of ten people from Wave 3 (epilepsy) who had high prosperity and levels of control that were as low as those 'just getting along' or even 'poor' was also analysed in order to understand more about this group of people with epilepsy. This is reported on at the end of the results section.

\subsection{Data analysis}

Frequencies and cross tabulations were used in order to gauge characteristics of all variables used in the study, and to identify key associations between prosperity and personal control. Oneway ANOVA have been used to identify and compare the three samples (Wave 3 (AELS), HILDA Wave 11 ALL and HILDA Wave 11 long term health conditions, disability or impairments) on levels of selfperceived prosperity in relation to level of personal control. The study has also used block recursive regression analysis to identify major determinants of personal control. This approach estimates total effects of all variables, which include direct and indirect effects through mediating variables.

The analysis was undertaken using the statistical package IBM Corp Released 2013 SPSS Statistics for Windows Version 22.0.

\section{Results}

Responses were received from three hundred and twenty four persons (or $36.7 \%$ of active registrants). Of these: 242 (76.6\%) were people with epilepsy; 74 (23.4\%) were people who completed the 
Table 1

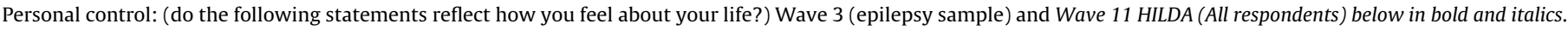

\begin{tabular}{|c|c|c|c|c|c|c|c|c|c|c|}
\hline & $\begin{array}{l}\text { Strongly } \\
\text { disagree }\end{array}$ & $\begin{array}{l}\text { Somewhat } \\
\text { disagree }\end{array}$ & $\begin{array}{l}\text { Slightly } \\
\text { disagree }\end{array}$ & Neutral & $\begin{array}{l}\text { Slightly } \\
\text { agree }\end{array}$ & $\begin{array}{l}\text { Somewhat } \\
\text { agree }\end{array}$ & $\begin{array}{l}\text { Strongly } \\
\text { agree }\end{array}$ & Total & Missing & $\begin{array}{l}\text { Mean } \\
\text { (scale 1-7) } \\
\text { (SD) }\end{array}$ \\
\hline There is no way & $53(19 \%)$ & $24(9 \%)$ & $18(6.5 \%)$ & $41(15 \%)$ & 38 (14\%) & 35 (13\%) & $65(23.5 \%)$ & 274 (100\%) & 50 & $4.28(2.21)$ \\
\hline $\begin{array}{l}\text { I can solve the } \\
\text { problems I have }\end{array}$ & $5084(33.5 \%)$ & 4649 (30. 6\%) & $1738(11.4 \%)$ & $1502(9.9 \%)$ & $1003(6.6 \%)$ & 727 (4.8\%) & 491 (3.2\%) & $15194(100 \%)$ & 2418 & $2.53(1.65)$ \\
\hline Sometimes I feel & 54 (19.5\%) & 24 (8.5\%) & 15 (5.5\%) & $49(18 \%)$ & $60(21.5 \%)$ & 47 (17\%) & $28(10 \%)$ & 277 (100\%) & 47 & 4.05 (1.99) \\
\hline $\begin{array}{l}\text { I am being pushed } \\
\text { around in life }\end{array}$ & $5555(36.6 \%)$ & 4007 (26.4\%) & $1689(11.1 \%)$ & $1644(10.8 \%)$ & $1196(7.9 \%)$ & 715 (4.7\%) & $361(2.4 \%)$ & $15167(100 \%)$ & 2445 & $2.51(1.65)$ \\
\hline I have little control & $44(16 \%)$ & $49(18 \%)$ & $27(10 \%)$ & $39(14 \%)$ & $48(17.5 \%)$ & 37 (13.5\%) & $31(11 \%)$ & 275 (100\%) & 49 & 3.85 (1.99) \\
\hline $\begin{array}{l}\text { over things that } \\
\text { happen to me }\end{array}$ & $4620(30.4 \%)$ & 4273 (28.1\%) & 1967 (12.9\%) & $1942(12.8 \%)$ & $1131(7.4 \%)$ & $730(4.8 \%)$ & 549 (3.6\%) & $15212(100 \%)$ & 2400 & $2.68(1.68)$ \\
\hline I can do just about & $18(6.5 \%)$ & $22(8 \%)$ & $26(9 \%)$ & $41(15 \%)$ & $54(20 \%)$ & $64(23 \%)$ & 51 (18.5\%) & 276 (100\%) & 48 & $4.76(1.73)$ \\
\hline $\begin{array}{l}\text { anything I set my } \\
\text { mind to }\end{array}$ & $506(3.3 \%)$ & $533(3.5 \%)$ & $828(5.4 \%)$ & 1949 (12.8\%) & 3096 (20.4\%) & 4540 (29.9\%) & 3749 (24.7\%) & 15201 (100\%) & 2411 & $5.32(1.54)$ \\
\hline I often feel helpless & 43 (15.5\%) & 45 (16.5\%) & $26(9.5 \%)$ & $38(14 \%)$ & $60(22 \%)$ & $37(13.5 \%)$ & $25(9 \%)$ & $274(100 \%)$ & 50 & $3.87(1.93)$ \\
\hline $\begin{array}{l}\text { dealing with } \\
\text { problems in life }\end{array}$ & $5550(36.5 \%)$ & 4449 (29.3\%) & $1656(10.9 \%)$ & $1498(9.8 \%)$ & $1071(7.0 \%)$ & $616(4.0 \%)$ & $370(2.4 \%)$ & $15201(100 \%)$ & 2402 & $2.44(1.60)$ \\
\hline What happens to me & $13(5 \%)$ & $14(5 \%)$ & $9(3.5 \%)$ & $38(14 \%)$ & 48 (17.5\%) & $62(22.5 \%)$ & $89(32.5 \%)$ & $273(100 \%)$ & 51 & $5.33(1.71)$ \\
\hline $\begin{array}{l}\text { in future mostly } \\
\text { depends on me }\end{array}$ & 708 (4.7\%) & $618(4.1 \%)$ & $622(4.1 \%)$ & $1440(9.5 \%)$ & $2131(14.0 \%)$ & 4936 (32.5\%) & 4748 (31.2\%) & 15203 (100\%) & 2409 & $5.46(1.65)$ \\
\hline There is little I can & $51(18.5 \%)$ & 57 (20.5\%) & $29(10.5 \%)$ & $52(19 \%)$ & 33 (12\%) & $29(10.5 \%)$ & $24(9 \%)$ & 275 (100\%) & 49 & $3.52(1.93)$ \\
\hline $\begin{array}{l}\text { do to change many } \\
\text { important things } \\
\text { in my life }\end{array}$ & 4687 (30.8\%) & $4534(29.8 \%)$ & $1890(12.4 \%)$ & 1808 (11.9\%) & 1073 (7.1\%) & 744 (4.9\%) & $462(3.0 \%)$ & $15198(100 \%)$ & 2414 & $2.61(1.65)$ \\
\hline
\end{tabular}

survey on behalf of a person with epilepsy; 8 were missing. Further: $67.5 \%$ of the respondents were females and $32.5 \%$ were males (with 22 missing data). Average age was 39.8 years; $34.4 \%$ had a university degree or postgraduate qualifications and $46.6 \%$ were currently in paid employment.

A diagram (below) shows the relationships of prosperity and control and mediating influences in the study. to determine where perceived prosperity lay in the context of other important epilepsy variables. Total effects of regression coefficients were estimated. Key effects on those experiencing higher control were firstly those experiencing low stigma, those in employment, and finally those having no seizures (the omitted category) compared to those experiencing up to at least one seizure per week in the last 12 months.

Perceived as prosperous-----Higher personal control----Potentially better experience of epilepsy

(Mediated by seizure frequency, employment and stigma)

Table 1 provides the results on levels of control experienced by all respondents in Wave 3 (epilepsy sample) and HILDA ALL sample.

\subsection{Personal control}

It is useful to contrast the levels of control people with epilepsy consider they have with responses from Wave 11 of HILDA (HILDA All). There was far higher agreement from the HILDA All sample for the following statements: 'there is no way I can solve the problems I have'; 'sometimes I feel I am being pushed around in life'; 'I have little control over things that happen to me'; 'I often feel helpless dealing with problems in life'; and 'there is little I can do to change many important things in my life.' There is higher agreement by the HILDA ALL respondents compared to Wave 3 epilepsy respondents that 'I can do just about anything I set my mind to'; and 'what happens to me in future mostly depends on me'. These differences in levels of control between the two surveys are reflected throughout.

\subsection{Perceived prosperity, seizure frequency, employment, stigma and personal control}

A block recursive regression analysis was undertaken of predictors of control in the Wave 3 (epilepsy) sample in order
Perceiving themselves as prosperous had no significant effect on personal control (see Table 2). The effect of experiencing stigma was quite strong. The experience of one point of stigma out of the 10 point stigma scale reduced personal control by more than 4 per cent. The difference in personal control between a person having no stigma and one experiencing total stigma is a reduction in personal control of 42 per cent. Those not in employment were likely to experience nearly 8 per cent less in personal control. In addition the net effect of experiencing at least one seizure per week compared to no seizures is likely to lead to more than an 8 per cent reduction in personal control. Level of prosperity had no significant effect. A higher education had a positive but not significant effect on control while seizure control as a result of current treatments did not have a significant effect. Thirty-two per cent of variation in

Table 2

Predictors of personal control.

\begin{tabular}{llll}
\hline \multicolumn{4}{l}{ Dependent: personal control (total effects estimated) (Scale 0-100) } \\
\hline & $b$ & beta & $p$ \\
\hline Stigma (scale 0-10) & -4.20 & -.47 & .000 \\
One seizure or more per week & -8.34 & -.13 & .033 \\
In paid employment & -7.63 & -.17 & .004 \\
Prosperity & .33 & .01 & .825 (ns)
\end{tabular}

Adjusted $R^{2} .32$.

ns, not significant. 


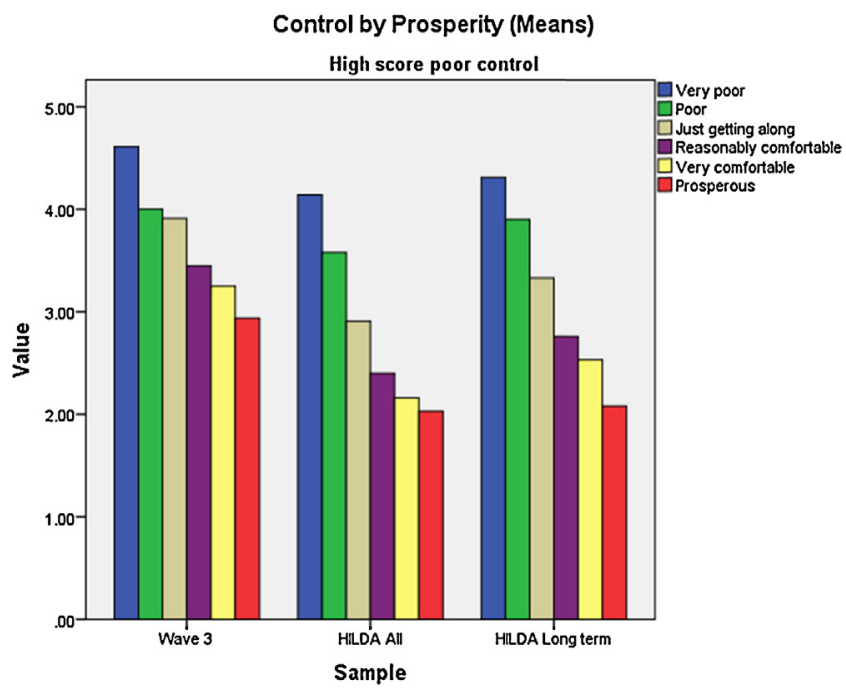

Fig. 1. Control by prosperity.

personal control and mastery was provided by the model, indicating a moderate amount of variation in personal control explained.

Social support was not measured; however epilepsy and its treatment had a strong effect on social relations of people with epilepsy. More than one third (40.3\%) said their relationship with their partner was affected by their epilepsy and its treatment; more $(43.3 \%)$ said this of their relationships with other family members and a similar proportion (42\%) considered their relationships with friends was affected.

\subsection{Epilepsy, self-perceived prosperity and personal control}

The extent to which epilepsy plays a negative role in the lives of people with epilepsy can be seen when prosperity is associated with levels of personal control. A number (42 or 14\%) of people in Wave 3 AELS (epilepsy) self-reported as prosperous or very comfortable. Following the hypothesis that higher prosperity would lead to a greater sense of control, a comparison was undertaken of similar groups in HILDA Wave 11, both the entire sample and those with a long term health condition, disability or impairment.

The following figures demonstrate the relationships between level of perceived prosperity and personal control in Wave 3, comparing these relationships with both HILDA Wave 11 samples. On the scale of personal control and prosperity it can be seen in Fig. 1 that Wave 3 people (with epilepsy) report a much poorer level of control overall on all dimensions of perceived prosperity than people in HILDA All (the entire sample) (Wave 11) and in HILDA, those with a long term health condition, disability or impairment. As expected the latter report slightly less control than the total HILDA sample.

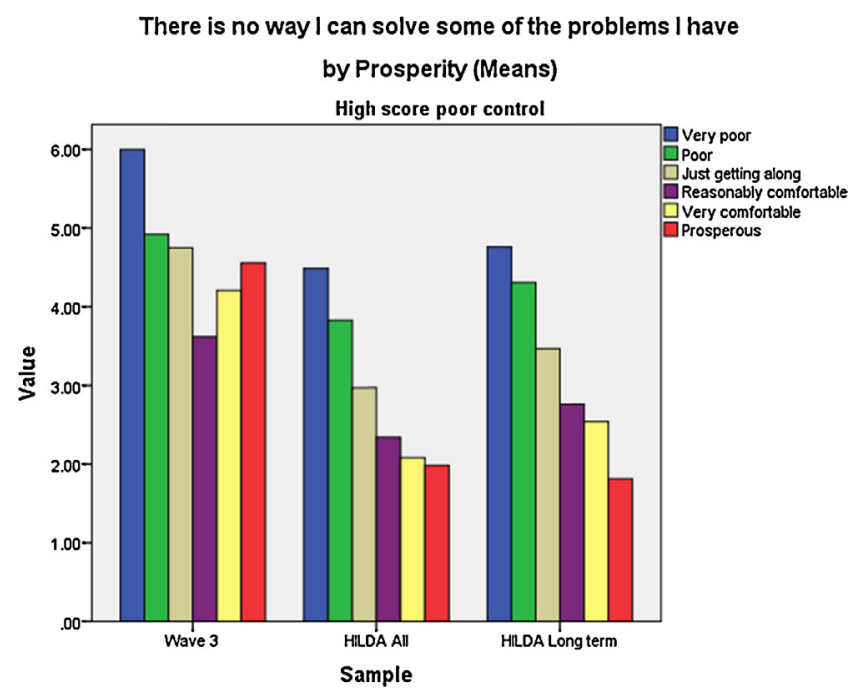

Fig. 2. Problem solving by prosperity.

In the two domains of personal control represented by the statements: 'There is no way I can solve the problems I have'; and 'I have little control over things that happen to me' the strong relationship with prosperity found in the two HILDA samples was not found in the Wave 3 (epilepsy) sample. Oneway ANOVA scores for these two variables are presented in Table 3 comparing Wave 3 (epilepsy) with HILDA All and with HILDA long term conditions, disability or impairment samples. Scheffe post hoc tests are discussed in the text.

In Wave 3 while there was a small significant relationship between level of prosperity and 'there is no way I can solve some of the problems I have' (see Table 3 ).

In Fig. 2 the 'very poor' in Wave 3 agree that they cannot solve the problems they have, and the 'poor' mostly do. About $60 \%$ of those 'just getting along' slightly to strongly agree they cannot solve their problems, while about only $40 \%$ of the 'reasonably comfortable' slightly to strongly agree. Surprisingly half of the 'very comfortable' slightly to strongly agree they cannot solve their problems and level of control diminishes for the prosperous. Rather than a strong relationship between prosperity and personal control this suggests a curvilinear relationship for the epilepsy sample'.

In the HILDA All sample only approximately $11 \%$ of those reasonably comfortable slightly to strongly agree there is no way they can solve their problems. As prosperity increases so does personal control and this is not found in the Wave 3 sample of people with epilepsy. Scheffe post hoc tests showed greatest differences for the HILDA All sample.

Of the HILDA sample with long term health conditions, disability or impairment, $4 \%$ of the prosperous, $15 \%$ of the very comfortable and $20 \%$ of the reasonably comfortable report a higher

Table 3

Personal control by prosperity (One Way ANOVA).

\begin{tabular}{|c|c|c|c|c|c|c|}
\hline & Sample & $F$ & $d f$ & $p$ & $n$ & Missing \\
\hline \multirow{3}{*}{$\begin{array}{l}\text { There is no way I can solve some of } \\
\text { the problems I have }\end{array}$} & Wave 3 & 2.46 & 5 & $.034^{*}$ & 241 & 83 \\
\hline & HILDA All & 216.68 & 5 & $.000^{* *}$ & 15194 & 2418 \\
\hline & HILDA Long term conditions, disability or impairment & 56.18 & 5 & $.000^{* *}$ & 3510 & 623 \\
\hline \multirow{3}{*}{$\begin{array}{l}\text { I have little control over things that } \\
\text { happen to me }\end{array}$} & Wave 3 & 1.91 & 5 & .093 & 242 & 82 \\
\hline & HILDA All & 127.61 & 5 & $.000^{* * *}$ & 15212 & 2400 \\
\hline & HILDA Long term conditions, disability or impairment & 51.57 & 5 & $.000^{* *}$ & 3515 & 618 \\
\hline
\end{tabular}

\footnotetext{
${ }_{* *}^{*}<.05$.

$* * 001$
} 


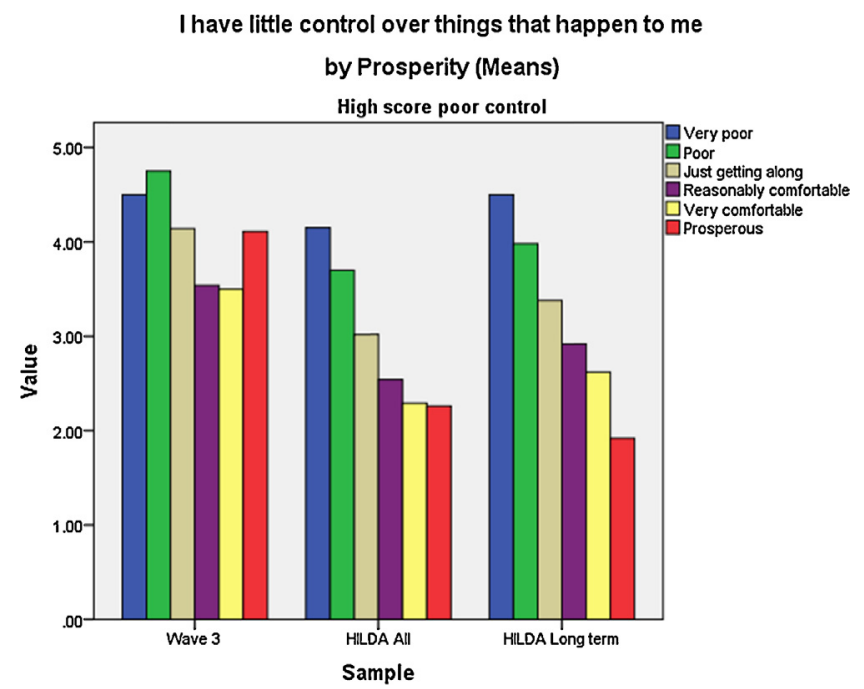

Fig. 3. Control over things that happen by prosperity.

control, demonstrating a strong and significant relationship between prosperity and control (see Table 3).

There was no significant relationship between level of prosperity and 'I have little control over things that happen to me' for Wave 3 (epilepsy) sample (Table 3 ).

In Fig. 3 more than half $(55.5 \%)$ of those who perceived themselves as prosperous agreed with the statement 'I have little control over things that happen to me' while $28 \%$ of the very comfortable and over $35 \%$ of the reasonably comfortable report lower levels of control. More than half $(58.5 \%)$ of those who considered themselves poor, slightly to strongly agreed. A quarter of the very poor also strongly agreed. There is a strong relationship between prosperity and levels of control with low control for the poor and very poor and high control for those who are more comfortable and prosperous in both of the HILDA samples. For the HILDA long term conditions, disability or impairment subset $36 \%$ of the poor and $58 \%$ of the very poor reported having little control over the things that happened to them.

However there were significant differences for the HILDA All sample and HILDA long-term conditions, disability and impairment (Table 3). Post hoc tests showed strongest differences for the HILDA All sample.

\subsection{Characteristics of Wave 3 participants with high prosperity and levels of control as low as less prosperous groups}

In the Wave 3 epilepsy sample despite considering themselves prosperous, ten people reported a level of personal control similar to those reporting lower prosperity. The following provides a picture of the epilepsy and health status of this group. Four of the ten said epilepsy and its treatment affected their social lives and all activities greatly, including their ability to drive. Additionally their ability to work and the kind of work they could undertake was affected. Four people considered that epilepsy affected their plans and ambitions for the future. Three reported that epilepsy affected their confidence and ability to be good parents a lot. Of these ten, five were taking two medicines. Additionally the same people reported injuries and hospitalisations due to seizures, frequent seizures, and lack of employment, bullying, fatigue, memory loss, hair problems, weight gain and cognitive impairment. Of the prosperous people in this Wave 3 (epilepsy) study with control at the level of lower prosperity groups some reported a number of comorbid conditions such as allergies, brain injuries, mental illness and depression, migraine, cardiovascular disease and emotional swings.

\section{Discussion}

The article explores whether 'well-off' people with epilepsy experience greater personal control in their lives than do those who are poor or "not well-off". This exploration was undertaken by comparing the Wave 3 Australian Epilepsy Longitudinal Survey with a wider HILDA Wave 11 Australian longitudinal survey, which included a subset of people with long-term health conditions, disability or impairments.

The HILDA All sample supported previous research that being well-off or prosperous influences the level of personal control people feel able to exercise in their lives. The smaller sample from HILDA of people with long term health conditions, disability or impairments also demonstrated a strong relationship between prosperity and personal control. This was not the case in the small sample of people from Wave 3 with epilepsy who perceived themselves as well off or prosperous. The results reveal complex relationships between perceptions of personal control and other variables which might be said to dilute the effects of feeling welloff or prosperous in epilepsy.

In the case of this epilepsy sample, being in employment, not experiencing seizures or stigma as well as not taking multiple medicines were important factors to affect people's perception of their levels of personal control. Comorbidities and injuries associated with epilepsy were also important factors to impact on personal control. Seizure frequency, hair loss, weight gain, fatigue and hospitalisations were likely to reduce personal control. These were far more important than any perceptions of prosperity.

These findings are underscored by previous research. Jacoby ${ }^{26}$ argues that for people with epilepsy it is the unpredictable aspect of the condition and fear of having seizures that is especially distressing. Seizure frequency alone did not help to explain the lack of a positive relationship found between prosperity and some of the personal control scale items in the current study, although it helped to amplify the low level of control reported in the epilepsy sample compared to the two HILDA samples. Jacoby further argues that living with the uncertainty of having seizures can have important sociopsychological consequences relevant to personal control. $^{27-29}$ Thus personal control has been found to mediate seizure effects on quality of life. ${ }^{28}$ Smith et al., ${ }^{29}$ found that a particular antiepileptic drug they tested reduced seizures and consequently had an improved effect on quality of life including personal control. Other studies ${ }^{19}$ have shown that uncontrolled seizures were more likely to produce low levels of personal control. Taylor et al., ${ }^{30}$ report that it was seizure control, rather than material advantage that affected quality of life for people with new onset epilepsy which has important implications for the study reported here.

Schachter ${ }^{31}$ reports that quality of life for people with epilepsy could be improved by increasing their locus of control. Au et al., ${ }^{32}$ suggest using cognitive therapy. Schachter further argues that employment has important self-esteem and quality of life benefits for people with epilepsy. In this study reported it was found being in paid employment is just one factor that has important control benefits. $^{33}$

The sense of personal control in Wave 3 is far lower than for both samples of HILDA Wave 11. This is confirmed by Asadi-Pooya et al., ${ }^{34}$ in their sample of epilepsy patients. As has been argued factors relating to epilepsy, its treatment and consequences for social interaction play a strong role on personal control.

While the small numbers in the Wave 3 sample of people with epilepsy constitute a limitation in this research, the results open the way for further exploration in the roles played by personal control and socio-economic status generally in epilepsy as well as other conditions. Research of this nature must perforce be context 
specific since perceptions of both personal control and prosperity are relative to the society in which people live.

The context in which this research was carried out is that Australia is a relatively prosperous society with relatively high incomes compared with other parts of the world. In the Australian Epilepsy Longitudinal Survey nearly $85 \%$ of the 283 recording their individual incomes were on incomes below average weekly earnings, while more than half of the families had incomes below the average. Further, a substantial number of respondents live below the poverty line as established by the Federal government. ${ }^{35}$ In 2010 , the poverty line ( $50 \%$ of median income) for a single adult was \$A358 per week and for a couple with two children it was $\$ A 752 .{ }^{36}$

This suggests that close to half the individuals with epilepsy in Wave 3 on individual incomes were living below the current poverty line, while combined household incomes reduced this to under a quarter. Compare this to overall poverty statistics where it is estimated that some $14 \%$ of the Australian population live below the poverty line and that $27 \%$ of people with a disability in Australia live below the poverty line. ${ }^{37}$

A high proportion (55\%) were on defined low incomes, while a further potential 30\% were on relatively low incomes in terms of average weekly earnings. However, there was a large group ( $n=102$ or $58 \%$ ) of those not working who were on disability pensions. Those unable to work because of their epilepsy constitute the single greatest number apart from those who had retired ( $n=50$ or $25 \%$ ).

This would account for the small number of people with epilepsy who identified as well-off or prosperous. Further research in this area would require that such economic contexts were taken into account. Additionally as concepts of personal control and prosperity are reliant on perception, it is important that future research in this area employs validated scales such as has been used here. The findings of negative social and behavioural consequences of epilepsy, and the role of comorbid conditions warrants further research into the role of personal control.

\section{Conclusion}

Some high levels of educational attainment, for people with epilepsy do not automatically lead to full-time employment. People with epilepsy report lower SES and lower self-reported prosperity than the broader population of Australians captured by the HILDA surveys. Far more people with epilepsy consider themselves to be 'poor' and 'very poor' compared with the HILDA survey.

Of special note is the relationship between epilepsy and levels of prosperity. For the HILDA respondents the greater the prosperity, the greater the feeling that one can solve one's problems and make changes in one's life. Similarly for the HILDA sample with long-term conditions, disabilities or impairments the greater the level of prosperity reported, the greater the perception that one could exercise control in solving problems and making changes in one's life. This is not reflected in the lives of this community sample of people with epilepsy in Wave 3. Being prosperous or financially comfortable does not necessarily help people with epilepsy feel they have control over their lives or can solve problems, since factors associated with epilepsy such as seizure activity, comorbid conditions, and stigma far outweighed perceived benefits of prosperity. These results suggest the need to more fully understand the sociopsychological processes operating within the lives of people with epilepsy.

\section{Ethical approval}

We confirm that we have read the Journal's position on issues involve in ethical publishing and affirm that this report is consistent with those guidelines.Ethics approval was gained from Deakin University Human Research Ethics Committee (Ref 2013-011).

\section{Conflicts of interest}

The authors have none to declare.

\section{Acknowledgements}

We wish to thank the Epilepsy Foundation for the use of the Australian Epilepsy Research Register for this study, and the people who participated in the research. The research was supported by a grant from UCB Pharma.

\section{References}

[1]. Bandura A. Social cognitive theory. In: Vasta R, ed. In: Annals of Child Development, vol. 6: Six Theories of Child Development. Greenwich, CT: JAI Press; 1989:1-60.

[2]. Seeman M, Lewis S. Powerlessness, health and mortality: a longitudinal study of older men and mature women. Soc Sci Med. 1995;41:517-525.

[3]. Wilkinon RG, Pickett P. The Spirit Level: Why More Equal Societies Almost Always Do Better. London: Allen Lane; 2009.

[4]. Marmot MG, Furhrer R, Ettner SL, Marks NF, Bumpass LL, Ryff CD. Contribution of psychosocial factors to socioeconomic differences in health. Milbank Q. 1998; 76:403-448.

[5]. Marmot MG, Wilkinson RG. Psychosocial and material pathways in the relation between income and health: a response to Lynch et al.. BMJ. 2001; 322:1233-1236.

[6]. Peterson C, Stunkard AJ. Personal control and health promotion. Soc Sci Med. 1989;28:819-828

[7]. Pearlin L, Schooler C. The structure of coping. J Health Soc Behav. 1978;19:2-21.

[8]. Seeman M. Personal Control in Psychosocial Notebook. Research Network on SES and Health. San Francisco: University of California; 2008. http://www.macses.ucsf. edu/research/psychosocial/control.php Accessed 21.03.15

[9]. Skinner E. A guide to constructs of control. J Pers Soc Psychol. 1996;71:549-570.

[10]. Ross C, Mirowsky J. The sense of personal control: structural causes and emotional consequences. In: Aneshensel CS, Phelan JC, Bierman A, eds. In: Handbook of the Sociology of Mental Health. Netherlands: Springer; 2013:379-402.

[11]. OECD Education at a glance. OECD Indicators at a glance 2012. http://www.oecd. org/australia/EAG2012\%20-\%20Country\%20note\%20-\%20Australia.pdf Accessed 18.07.15.

[12]. Saunders P. A Perennial Problem: Employment, Joblessness and Poverty. SPRC Discussion Paper 146. 2006;12.

[13]. Oakes JM, Rossi PH. The measurement of SES in health research: current practice and steps towards a new approach. Soc Sci Med. 2003;56:773.

[14]. Draper G, Turrell G, Oldenburg B. Health Inequalities in Australia: Mortality. Health Inequalities Monitoring Series No. 1.. Canberra: Queensland University of Technology and the Australian Institute of Health and Welfare; 2004.

[15]. Turrell G, Stanley L, de Looper M, Oldenberg B. Health Inequalities in Australia: Morbidity, Health Risk Behaviours, Risk Factors and Health Service Use. Health Inequalities Monitoring Series No. 2.. Canberra: Queensland University of Technology Australian Institute of Health and Welfare; 2006.

[16]. Swerissen H, Belfrage J, Weeks A, et al. A randomised control trial of a selfmanagement program for people with a chronic illness from Vietnamese, Chinese, Italian and Greek backgrounds. Patient Educ Couns. 2006;64:360-368.

[17]. Ferrie J, ed. In: Work, Stress and Health: Findings from the Whitehall II Studies. International Centre for Health and Society Department of Epidemiology and Public Health London University College; 2004.

[18]. Goldman DP, Smith JP. Can patient self-management help explain the SES health gradient? Proc Natl Acad Sci. 2002;99:10929-10934http://www.pnas. org cgi_doi_10.1073 pnas.162086599 Accessed 25.01.15

[19]. McLaughlan DP, Pachene NA, McFarland K. The impact of depression, seizure variables and local control on health related quality of life in a community dwelling sample of older adults. Seizure. 2010;19:232-236.

[20]. Hermann B, Jacoby A. The psychosocial impact of epilepsy in adults. Epilepsy Behav. 2009;15:S11-S16.

[21]. Edwards RR, Telfair J, Cecil H, Lenoci J. Reliability and validity of a self-efficacy instrument specific to Sickle Cell Disease. Behav Res Ther. 2000:38:951-963.

[22]. Mindful Project Recommendations for the European Health Interview Survey EHIS Health Determinants Module. 2006. http://ec.europa.eu/health/ph_projects/2003/ action1/docs/2003_1_11_frep_a15_en.pdf Accessed 18.02.15

[23]. Lynch JW, Kaplan GA. Socioeconomic factors. In: Berkman LF, Kawachi I, eds. In: Social Epidemiology. New York: Oxford University Press; 2000:13-35.

[24]. Austin JK, McLeod J, Dunn DW, Shen J, Perkins SM. Measuring stigma in children with epilepsy and their parents; Instrument development and testing. Epilepsy Behav. 2004;5:472-482.

[25]. Peterson CL, Walker C, Shears G. The social context of anxiety and depression: exploring the role of anxiety and depression in the lives of Australian adults with epilepsy. Epilepsy Behav. 2014;34:29-33.

[26]. Jacoby A. Epilepsy and the quality of everyday life. Findings from a study of people with well-controlled epilepsy. Soc Sci Med. 1992;34:657-666. 
[27]. Kellet MW, Smith DF, Baker GA, Chadwick GW. Quality of life after epilepsy surgery. I Neurol Psychiatry. 1997;62:53-58.

[28]. Amir M, Rosimer J, Knoll A, Neufeld MY. Self-efficacy and social support as mediators in the relation between disease severity and quality of life in patients with epilepsy. Epilepsia. 1999;40:16-24.

[29]. Smith D, Chadwick D, Baker D, Davis G, Dewey M. Seizure severity and the quality of life. Epilepsia. 1993;34:S31-S35.

[30]. Taylor J, Jacoby A, Baker GA, Marson AG, Ring A. Factors predictive of resilience and vulnerability n new-onset epilepsy. Epilepsia. 2011;52:610-618.

[31]. Schachter SC. Improving quality of life beyond seizure control. Epileptic Disord. 2005; 7:S3-S9.

[32]. Au A, Chan F, Li K, Leung P, Li P, Chan J. Cognitive behavioural group treatment programs for adults with epilepsy in Hong Kong. Epilepsy Behav. 2003;4:441-446.
[33]. Szaflarski M. Social determinants of health in epilepsy. Epilepsy Behav. 2014:41:283-289.

[34]. Asadi-Pooya AA, Schilling CA, Glasser D, Tracy JI, Sperling MR. Health locus of control in patients with epilepsy and its relationship to anxiety, depression and seizure control. Epilepsy Behav. 2007;11:347-350.

[35]. Australian Government Dept. of Human Services. Income test for low income Health Care Card. http://www.humanservices.gov.au/customer/enablers/ centrelink/low-income-health-care-card/income-test Accessed 29.07.14.

[36]. Fair Work Australia, http://www.fairwork.gov.au Accessed 29.07.14.

[37]. Australian Council of Social Service (ACOSS) Poverty in Australia 2014. http:// www.acoss.org.au/images/uploads//ACOSS_poverty_in_Australia_2014.pdf Accessed 30.07.14. 